\title{
Enhancing vector refractoriness to trypanosome infection: achievements, challenges and perspectives
}

\author{
Henry M Kariithi ${ }^{1 \dagger}$, Irene K Meki ${ }^{3,4 \dagger}$, Daniela I Schneider ${ }^{5+}$, Linda De Vooght ${ }^{6 \dagger}$, Fathiya M Khamis ${ }^{7 \dagger}$, Anne Geiger ${ }^{8 \dagger}$, \\ Guler Demirbaş-Uzel ${ }^{\dagger \dagger}$, Just M Vlak ${ }^{4}$, ikbal Agah iNCE ${ }^{9}$, Sorge Kelm ${ }^{10}$, Flobert Njiokou ${ }^{11}$, Florence N Wamwiri ${ }^{12}$, \\ Imna I Malele ${ }^{13}$, Brian L Weiss ${ }^{5}$ and Adly M M Abd-Alla $a^{3,2^{*}}$
}

\begin{abstract}
With the absence of effective prophylactic vaccines and drugs against African trypanosomosis, control of this group of zoonotic neglected tropical diseases depends the control of the tsetse fly vector. When applied in an area-wide insect pest management approach, the sterile insect technique (SIT) is effective in eliminating single tsetse species from isolated populations. The need to enhance the effectiveness of SIT led to the concept of investigating tsetsetrypanosome interactions by a consortium of researchers in a five-year (2013-2018) Coordinated Research Project (CRP) organized by the Joint Division of FAO/IAEA. The goal of this CRP was to elucidate tsetse-symbiomepathogen molecular interactions to improve SIT and SIT-compatible interventions for trypanosomoses control by enhancing vector refractoriness. This would allow extension of SIT into areas with potential disease transmission. This paper highlights the CRP's major achievements and discusses the science-based perspectives for successful mitigation or eradication of African trypanosomosis.
\end{abstract}

Keywords: Glossina, Microbiota, Paratransgenesis, Vector competence, Trypanosoma-refractoriness, sterile insect technique, Hytrosaviridae

\section{Background}

Tsetse flies (Diptera; Glossinidae) transmit African trypanosomes across sub-Saharan Africa. These protozoan parasites are the causative agents of human and animal African trypanosomoses (HAT and AAT, respectively), which are neglected tropical diseases that are fatal if left untreated [1,2]. A lack of effective prophylactic vaccines and drugs that target trypanosomes $[3,4]$ makes control of the tsetse vector an appealing alternative to reduce disease transmission. One attractive vector control method is the sterile

\footnotetext{
* Correspondence: a.m.m.abd-alla@iaea.org

${ }^{\dagger}$ Henry M Kariithi, Irene K Meki, Daniela I Schneider, Linda De Vooght, Fathiya M Khamis, Anne Geiger and Guler Demirbaş-Uzel contributed equally to this work. ${ }^{3}$ Insect Pest Control Laboratory, FAO/IAEA Agriculture \& Biotechnology Laboratory, IAEA Laboratories Seibersdorf, A-2444 Seibersdorf, Austria

${ }^{2}$ Molecular Department, Vector and Vector Borne Diseases Institute, Tanzania Veterinary Laboratory Agency, Majani Mapana, Off Korogwe Road, Box, 1026 Tanga, Tanzania

Full list of author information is available at the end of the article
}

insect technique (SIT), which is effective when included as a component of an area-wide integrated pest management (AW-IPM) approach [5-8]. SIT involves the mass production of sterilized male adults, which subsequently out-compete wild males in mating with wild virgin females in the field [9]. These matings are non-productive, eventually resulting in the decline and elimination of the target wild insect populations [10].

The successful and sustained eradication of Glossina austeni Newstead and AAT from Unguja Island in 1997 [7], in which SIT played a pivotal role, inspired African Governments to implement similar campaigns against tsetse on mainland Africa. SIT has also been employed to suppress G. palpalis gambiensis and G. tachinoides populations in Burkina Faso, G. p. palpalis in Nigeria $[11,12]$, and G. pallidipes in Ethiopia [13]. Challenges associated with improving SIT effectiveness include successful colony establishment [14], management of pathogenic infections that reduce colony fitness $[15,16]$ and compromised performance of field-released sterile males 
[17]. Importantly, the ability of released sterile males to vector trypanosomes increases the risk of transmitting disease in foci where trypanosomes are actively circulating. Furthermore, irradiation used for sterilization may negatively impact tsetse fitness (e.g. by damaging the tsetse host and its associated beneficial microbiota [18, 19].

\section{The joint FAO/IAEA-sponsored coordinated research projects}

To enhance the SIT programs, the Joint Division of FAO/IAEA initiated a five-year (2013-2018) Coordinated Research Project (CRP) on enhancing tsetse fly refractoriness to trypanosome infections [20]. Composed of 22 research teams from 18 countries, the CRP involved four Research Coordination Meetings (RCMs) to review the results, progress and plan future research activities.

This paper highlights the major achievements towards answering the following four key research questions of the CRP: (1) Can the elucidation of tsetse-trypanosome molecular interactions assist in the development of novel methods and approaches to reduce or prevent the transmission of trypanosomes by irradiated tsetse flies? (2) Are tsetse's symbiome and the fly's competence as a vector of trypanosomes affected by radiation? (3) Can tsetse symbionts be used to develop novel vector and disease control tools, complementary to the SIT? (4) Can the characterization of tsetse's symbiome and viral pathogens improve the efficacy of SIT? [20]. Many other concepts that emerged while addressing the above-mentioned research questions were addressed during the course of the CRP.

\section{Major objective of the CRP}

The overall objective of the CRP was to elucidate the tsetse-symbiome-pathogen molecular interactions to improve SIT and SIT-compatible interventions. This effort was undertaken to reduce trypanosomosis by enhancing vector refractoriness, thus facilitating the expansion of SIT to areas where HAT-causing parasites are currently circulating in resident animals. The specific objectives and the expected output of this CRP are listed in Table 1 [See also Ref.\#20]. The improved knowledge gained from achieving the objectives of the CRP is of significant interest to the FAO/ IAEA and sub-Sahara African countries in their endeavor to control and ultimately eradicate tsetse and African trypanosomosis.

Table 1 The Five-year (2013-2018) CRP objectives, outputs and achievements (published papers)

\begin{tabular}{|c|c|c|}
\hline Specific objectives & Expected output & Published papers $^{a}$ \\
\hline $\begin{array}{l}\text { (i). Elucidate tsetse-trypanosome interactions and } \\
\text { understand determinants of vector competence. }\end{array}$ & $\begin{array}{l}\text { (i). Molecular interplay of tsetse-trypanosomes } \\
\text { characterized. } \\
\text { (ii). Factors affecting trypanosome infections in tsetse } \\
\text { determined. } \\
\text { (iii). Tsetse vectorial competence assessed via } \\
\text { comparative genomics and transcriptomics. }\end{array}$ & $\begin{array}{l}{[102-146] ;} \\
([21,26,43,107,147])\end{array}$ \\
\hline $\begin{array}{l}\text { (ii). Acquire better understanding of the physiology } \\
\text { of tsetse-microbiota-pathogen tripartite interactions. }\end{array}$ & $\begin{array}{l}\text { (i). Microbiota of multiple trypanosome-infected and } \\
\text { uninfected tsetse species and hybrids determined. } \\
\text { (ii). Trypanosome-microbiota interactions in model } \\
\text { tsetse species and hybrids determined. } \\
\text { (iii). Impacts of viral pathology on the tsetse symbionts } \\
\text { determined. }\end{array}$ & $\begin{array}{l}{[42,47,53,58,59,148-172]} \\
([44,54,72,93,173,174])\end{array}$ \\
\hline $\begin{array}{l}\text { (iii). Determine effects of radiation in tsetse, } \\
\text { its microbiota and pathogens. }\end{array}$ & $\begin{array}{l}\text { (i). Effects of radiation on tsetse vectors, their symbionts } \\
\text { and pathogens determined. } \\
\text { (ii). Mutagenic effect of radiation on paratransgenesis } \\
\text { determined. }\end{array}$ & {$[175] ;([95,99])$} \\
\hline $\begin{array}{l}\text { (iv). Analyse SGHV-microbiota interactions in multiple } \\
\text { tsetse species. }\end{array}$ & $\begin{array}{l}\text { (i). Functional SGHV genes identified as candidates for } \\
\text { developing antiviral mitigation strategy. } \\
\text { (ii). Latency SGHV genes identified as tools for host } \\
\text { interacting proteins. } \\
\text { (iii). Mechanisms of SGHV's escape from host defense } \\
\text { response determined. } \\
\text { (iv). SGHV haplotypes and evolution in lab-reared } \\
\text { and wild tsetse fly populations determined. }\end{array}$ & $\begin{array}{l}{[75,76,79,81,82,84,176,177] ;} \\
([28,77,78,80,83])\end{array}$ \\
\hline $\begin{array}{l}\text { (v). Develop novel symbiont-based, SIT-compatible } \\
\text { anti-trypanosomiasis strategies. }\end{array}$ & $\begin{array}{l}\text { (i). Wolbachia-based population suppression and/or } \\
\text { replacement strategies assessed. } \\
\text { (ii). Trypanosome-refractory paratransgenic tsetse lines } \\
\text { developed. }\end{array}$ & {$[94,108,178] ;([109])$} \\
\hline
\end{tabular}

${ }^{a}$ Articles in round brackets are published in the current issue of the BMC Special Issue. The remaining articles in this table have either been or are submitted for publication elsewhere during the five years (2013-2018) CRP period 


\section{Current status and achievements}

During the course of the CRP (2013-2018) more than seventy scientific papers, detailing experimentally derived data related to achieving the project's objectives, were published in peer reviewed journals. This special issue includes several of these papers, findings from which are briefly summarized in this introductory chapter along with the overall outcome of the project and future perspectives.

\section{Tsetse species resolution}

Correct taxonomic identification of insects is imperative for many reasons including the fact that studies conducted on different taxa may be reported by the same species (names), thus creating confusion. It is therefore important to properly identify field-captured tsetse species during characterization of their inhabiting microbial communities (including parasites, pathogens and symbionts). During the CRP, Augustinos and colleagues [21; this issue] evaluated the use of different molecular tools that can be used to efficiently and accurately distinguish distinct Glossina species using samples deriving from laboratory colonies and museum collections as well as all those collected in the field. The combined use of relatively inexpensive molecular genetic techniques, along with the identification of species specific microsatellites and mitochondrial and nuclear markers, will facilitate accurate identification of several tsetse species in the future.

\section{Tsetse-microbiota-trypanosome interactions and determinants of vectorial competence}

Figure 1 summarizes the interwoven associations and localization of the tsetse's microbiota, which is comprised of the Wigglesworthia-Sodalis-Wolbachia complex, recently discovered Spiroplasma, environmentally acquired enteric bacteria, the salivary gland hypertrophy virus (SGHV) and the Trypanosoma parasite.

\section{Trypanosome co-infections in tsetse flies}

Molecular epidemiological surveys indicate that tsetse fly midguts, sampled from various HAT and AAT foci (including Fontem [22, 23] Campo and Bipindi [22, 24], Bafia [25] and Faro and Deo [26; this issue] in Cameroon) are infected with multiple trypanosome species. Application of nuclear ribosomal internal transcribed spacer (ITS) and/or trypanosome species-specific primers revealed that $53-82 \%$ of flies housed infections with trypanosome of a single species ( $T$. brucei sl., $T$. congolense "forest" and "savannah" types, T. vivax and T. simiae), $18-47 \%$ were infected with two or three of the aforementioned species. In the Malanga HAT focus in Democratic Republic of Congo, $13.87 \%$ and $1.9 \%$ of G. p. palpalis

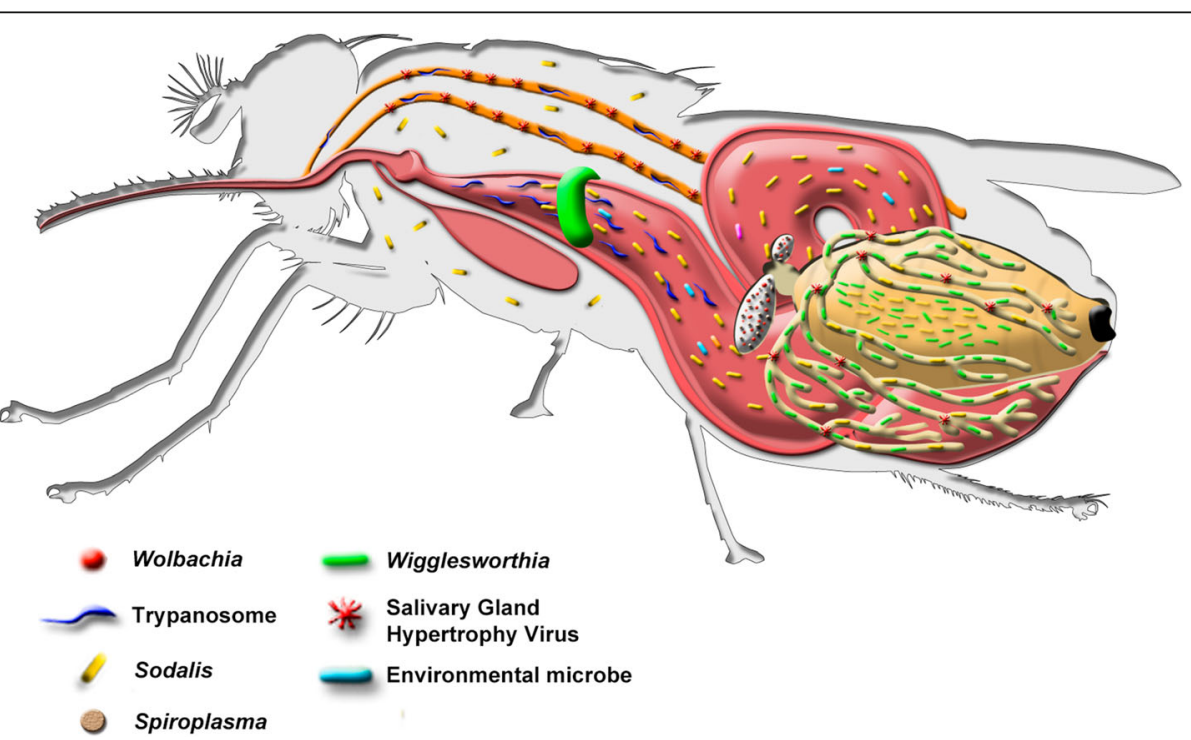

Fig. 1 The tsetse fly and its associated microorganisms. Tsetse flies can harbor multiple microbes, including the bacterial endosymbionts obligate Wigglesworthia, facultative Sodalis, parasitic Wolbachia and Spiroplasma, as well as a taxonomically diverse population of environmentally acquired enteric bacteria, a virus (salivary gland hypertrophy virus, SGHV) and protozoan African trypanosomes. All tsetse harbor Wigglesworthia, while the presence of Sodalis, Wolbachia, Spiroplasma, SGHV and trypanosomes is fly population dependent. Wigglesworthia, Sodalis and SGHV are transmitted to developing intrauterine larval offspring via maternal milk secretions, while Wolbachia is transmitted through the germline. Spiroplasma's mode of vertical transmission is currently unknown. Pathogenic trypanosomes are acquired by tsetse when they feed on an infected animal. The parasites must then undergo a complex development cycle in the fly before they can be successfully transmitted to a new host, where they cause disease. (This figure is adapted with permission from Aksoy et al., 2013) [179] 
had single and mixed trypanosome infections, respectively [27]. To assess the prevalence of trypanosome infection in a geographically broader area, Ouedraogo et al. [28; this issue] screened 3102 individual tsetse flies comprised of four species collected in five countries in west Africa. Results from this study indicate that trypanosome infections prevalence varied between tsetse species and location, but was on average substantial. In other words, infection prevalence ranged widely from $2.2-61.1 \%$ in flies sampled from different species in different locations. Furthermore, mixed infection was rarely observed $(<10 \%)$, and could be attributed to host specificity and/or preferences (human, domestic and wild animals) of particular tsetse species [29-32] and/or sensitivity of the PCR assay.

\section{Modulations of tsetse gene expression during trypanosome infections}

During SG infections, $T . b$. brucei suppresses the expression of the most abundant proteins in G. m. morsitans SGs, especially the proteins involved in the blood feeding process (e.g. Tsal1/2, TAg5, TSGF-1/2, 5'-Nuc, ADA and Spg3) [33]. This reduction in protein expression may significantly reduce fly feeding performance, consequently promoting vector competence via increase of the fly's biting frequency. Further, the parasite upregulates expression of specific host proteins that are essential for parasite maturation, particularly proteins (e.g. CaMK, Serp-2, V-ATPases, and ArgK) involved in the regulation of stage-specific parasite differentiation $[33,34]$. In response to the SG infection, tsetse overexpresses at least 15 immunity-related proteins [See Table 3 in Ref.\#33]. In the midguts of G. pallidipes, which is more refractory to midgut colonization by trypanosomes compared to G. m. morsitans [35], T. b. brucei-challenge did not significantly modulate most of the genes (>93\%) in infected flies compared to uninfected controls [36]. However, whereas $T$. b. brucei induced expression of metabolism-associated genes in teneral flies $(24 \mathrm{~h}$ post challenge), immunity-related and oxidative stress (ROS) genes were induced during late infection stages $(48 \mathrm{~h}$ post challenge) [36]. Induction of expression of immunity and ROS genes is partially implicated in trypanosome-refractoriness in G. m. morsitans [37]. Notably, unlike in G. m. morsitans, in which only a small proportion of midgut infections progress to the SG, all G. pallidipes with trypanosome gut infections end up hosting mature SG infections [35]. Together, these data are applicable in designing strategies to interfere with metacyclogenesis and transmission of the mammalian-infective metacyclic (MT) parasites in the SGs of G. pallidipes. The SG tissue bottleneck (in trypanosome transmission) represents a vulnerable and attractive intervention point to enhance natural tsetse refractoriness to trypanosomes or to reduce the vectorial competence of the sterile males used in SIT campaigns.

\section{Role of Sodalis in the establishment of trypanosome infections in tsetse midguts}

Sodalis glossinidius, tsetse's facultative endosymbiont, may modulate the ability of trypanosomes to establish an infection in tsetse's midgut. However, the mechanism(s) that underlies this association is poorly understood [38-40]. This CRP addressed this knowledge gap by further exploring the relationship between Sodalis and trypanosome infection in tsetse. Geiger et al. [41] observed a correlation between specific Sodalis genotypes and tsetse's ability to establish trypanosomes infection.

Hamidou et al. [42] demonstrated that Sodalis-hosted prophages also mediate trypanosome infection establishment by affecting Sodalis densities. However, certain studies on field-caught tsetse did not indicate any strong associations between Sodalis densities and trypanosome infections [26; this issue, 43; this issue]. In addition, a correlation between trypanosome infection and Sodalis presence observed in Kenya [43; this issue] was weak or nonexistent. However, the authors thought that tsetse-trypanosome-microbiota interactions could be influenced by other factors such as tsetse's ecology and community compositions, but only in some species of trypanosomes. However, Griffith et al., [44; this issue] found that Sodalis densities were significantly higher in trypanosome-infected, wild-caught flies compared to their uninfected counterparts. Additionally, other confounding factors may indirectly affect vectorial competence, including tsetse flies age, sex, habitat, species of trypanosome, and Sodalis genotypes and their modulation of the host's immune system [43, this issue]. These factors may influence Sodalis densities, which may indirectly impact trypanosome prevalence within tsetse and the fly's vectorial competence for trypanosome transmission.

\section{Insights into tsetse-microbiota-pathogen tripartite interactions}

\section{Tsetse symbionts}

Taxonomic composition of microbial communities housed in the gut of wild tsetse

Enteric microbes impact several aspects of their host's physiology [45]. In tsetse, the obligate mutualist Wigglesworthia mediates numerous aspects of the fly's physiology, including nutrition, reproduction and immune system maturation and function [46-48]. Over the course of this CRP, researchers performed studies to characterize the taxonomic composition of 
environmentally acquired bacteria housed in the gut of field-captured and colonized tsetse. This information is an important prelude to understanding how this population of microbes impacts tsetse's fitness and susceptibility to trypanosome infection. Using culture dependent and independent techniques, prominent bacterial taxa found in guts from field captured tsetse included Serratia, Enterobacter, Enterococcus, Acinetobacter, Providencia, Sphingobacterium, Chryseobacterium, Lactococcus, Staphylococcus, and Pseudomonas, Bacillus, Mesorhizobium, Paracoccus, Microbacterium, Micrococcus, Arthrobacter, Corynobacterium, Curtobacterium, Vagococcus, and Dietzia spp. ([44, 49-54]; this issue). The sources and mechanisms by which tsetse flies acquire this diverse enteric microbiota remain unclear. However, tsetse hosts from specific ecosystems could differ in their microbial diversities [55]. Flies could ingest bacteria present on host skin when probing for a blood meal [56], or host blood may contain bacteria that are ingested by flies during feeding on a septic host. Identification of diverse bacteria in tsetse tissues that also house trypanosomes raises the question whether these bacteria influence trypanosome infections. Environmentally acquired bacteria found in the gut of other disease vectors (i.e., Anopheles gambiae) exhibit direct anti-parasitic properties [57]. As such, tsetse's gut microbiota should be explored in more detail to determine if bacteria that exhibit anti-trypanosomal properties are present in the fly's gut.

\section{Discovery and characterization of Spiroplasma, a potential fourth symbiont of tsetse}

One of the major achievements of this CRP is the discovery of Spiroplasma as a fourth endosymbiont (in addition to Wigglesworthia, Sodalis, and Wolbachia) in some wild and laboratory-reared tsetse populations [58, 59]. While the function of this bacterium in tsetse is currently unknown, it likely to impact colony fitness. However, in Drosophila, Spiroplasma is a maternally [60] and horizontally transmitted mutualist [61]. Some lineages of Spiroplasma confer their hosts with important traits, including defense against pathogens (e.g. parasites and bacteria), either singly or in associations with other symbionts such as Wolbachia [62-65]. The poorly understood mechanism(s) of Spiroplasma-Wolbachia associations presents an intriguing research topic, given that Wolbachia (found mainly in reproductive organs) and Spiroplasma (resides primarily in the hemolymph, but can also invade other tissues such as ovaries, fat body and SGs) exhibit similar tissue tropisms. Research on the Glossina-Spiroplasma association is required to determine if the bacterium presents commensal, mutualist or pathogenic phenotypes in the fly. Additionally, it will be important to determine the relationship between Spiroplasma and other constituents of tsetse's microbiota, including bacterial symbionts, viral pathogens and trypanosomes. Finally, studies should be performed to determine if Spiroplasma can be utilized to develop novel symbiont-based strategies aimed at blocking trypanosome transmission.

\section{Role of Wolbachia in tsetse speciation and generation of fertile hybrid tsetse colonies}

Symbiont-induced cytoplasmic incompatibility (CI) acts as an efficient post-mating barrier to hybrid formation, making it an important parameter in preserving species borders [66-69]. In tsetse, Wolbachia efficiently triggers CI within [70] and between species [71]. During the CRP, Wolbachia related research focused on two main topics: 1) the development of diagnostic tools sensitive to detect low titer Wolbachia infections in tsetse species, and 2) exploration of $\mathrm{Wol}$ bachia's role in tsetse speciation. In relation to the first topic, Schneider et al. [72; this issue], compared classic endpoint PCR with high-sensitivity blot-PCR and demonstrated that the latter technique facilitates more sensitive detection of low-titer Wolbachia in the morsitans and palpalis groups than does classic endpoint PCR. In addition, the authors used a high-end Stellaris $^{\oplus}$ rRNA-FISH based technique to localize $\mathrm{Wol}$ bachia in situ in high and low-titer Glossina species, and demonstrated that with this highly sensitive method, even low amounts of Wolbachia can be traced in specific tissues. The results also highlight that more tissues and organs than previously recorded are infested with Wolbachia in subspecies of the morsitans and palpalis groups. The novel, highly sensitive molecular Wolbachia detection tools developed during the CRP [72; this issue] should expedite further investigations on the tsetse hybrid colonies.

With regard to Wolbachia's role in tsetse speciation, previously published data indicate that mating between Wolbachia-free G. morsitans females and wild type G. morsitans males results in significantly reduced larval deposition and adult eclosion rates [70]. Similarly, mating between wild type G. morsitans and G. centralis triggers high CI levels due to the presence of two incompatible Wolbachia strains [71]. However, premating barriers to hybrid formation are rather weak or completely absent, as members of various Glossina species mate readily [73]. Nevertheless, the negative effects of $\mathrm{CI}$ led to the consideration of generating tsetse hybrids for population control [74]. This consideration is based on the assumption that among artificially created hybrids between closely related Glossina species, males are post-zygotically incompatible with both parental species due to their natural hybrid sterility. Such pseudo-sterile tsetse males can be complementary to the SIT programs. 
Experiments performed during the CRP demonstrated that knockdown of native Wolbachia in G. m. morsitans males prior to their mating with G. m. centralis females results in successful establishment of a hybrid line, which is now maintained in the IPCL tsetse production facility in Seibersdorf, Austria (unpublished data). Therefore, prior to employing hybrid flies to existing SIT programs, further investigations are necessary to determine how symbiont status and mating competence are affected in the hybrid background, and whether the hybrids and wild type flies are equally fit.

\section{Tsetse fly pathogens}

In addition to microbial communities associated with tsetse flies, pathogens such as the SGHV (Hytrosaviridae) and entomopathogenic fungi (EPF) infect tsetse flies and hence affect fly fitness both in insect mass rearing facilities and in the field. During the CRP, research was conducted to gain a better understanding on the impact of these pathogens on tsetse fly fitness and susceptibility to trypanosomes.

\section{Salivary gland hypertrophy viruses}

\section{Pathobiology of GpSGHV haplotypes and the prospects for integrated antiviral strategies}

Over the course of the CRP, the following topics related to SGHV were investigated: 1) improvement of virus control strategies [75], 2) explore genomic differences between virus isolates [76], 3) virus host range [77], 4) the impact of virus infection on tsetse fitness, 5) genetic diversity of field collected viral isolates, and 6) the impact of virus infection on the expression of tsetse immune genes. Comparative analyses of the Ethiopian and Ugandan GpSGHV strains [76] suggest that the differential virus-pathologies (i.e. outbreaks of the salivary gland hypertrophy symptoms, SGH) in G. pallidipes colonies are due to factors such as differences in viral gene contents, host genetics and ecologies, and virus-host coevolutionary histories [78]; this issue. GpSGHV pathological effects and the host's response to the virus infection vary amongst different Glossina species. For instance, in G. pallidipes, GpSGHV infection results in significant upregulation of host genes associated with pathways promoting viral infection compared to upregulation of genes associated with antiviral responses in virus-infected G. m. morsitans [79]. We now have clues that more GpSGHV strains exist in multiple Glossina species, and that G. pallidipes may influence GpSGHV evolution [78, 80]; this issue. Susceptibilities of tsetse to GpSGHV infections, and the negative impacts of viral infections on the fly's fecundity, adult eclosion and survival, differ amongst different fly species [77, 81]; this issue. The narrow GpSGHV host range (only in Glossina species) and lack of overt SGH in the majority of tsetse hosts do not preclude implementing precautionary antiviral measures in tsetse production facilities that rear multiple species $[15,16,78,82]$.

\section{Insights into the roles of tsetse immunity during symptomatic GpSGHV infections in lab-bred tsetse colonies}

We have ascertained that GpSGHV infection provokes the RNA interference (RNAi) defense response, as evidenced by significant upregulation of the expression of key RNAi pathway genes (Ago-1, Ago-2 and Dcr-2) in virus-injected flies (asymptomatically infected) compared to the non-infected flies [83; this issue]. These data imply that both siRNA and miRNA pathways (two of the RNAi machinery pathways) provide antiviral defense in asymptomatic infected flies, but the pathways are highly compromised during symptomatic infections. The third RNAi machinery pathway (piRNA pathway) appeared not to be involved in tsetse's defense mechanism against GpSGHV, as virus infection did not affect the expression of Ago-3 gene, a key gene in the piRNA pathway [83]. In addition to the RNAi, we have indications that GpSGHV infection alters the host miRNA profile in G. pallidipes, thus indicating possible functional importance of miRNAs in symptomatic infections [84; MS in Prep.]. Notably, the majority of the upregulated miRNAs were predicted to target over 700 host mRNAs, of which 150 mRNAs were immune-related. miRNA expression profiles are also modulated by the insect microbiota, and may therefore contribute to the outcomes of virus infection as has been demonstrated in the dengue mosquito vector Aedes aegypti [85]. Recent data suggest that the absence (or low densities) of Wolbachia positively correlates with SGHV outbreaks in G. pallidipes colonies compared with other Glossina species that rarely exhibit overt SGH symptoms [86]. Whether differences in Wolbachia prevalence in tsetse species is linked to differences in GpSGHV infections (e.g. via modulations of miRNAs) requires further investigations.

\section{Entomopathogenic fungi}

EPF have been proposed as potential mosquito control agents [87]. The EPF Metarhizium anisopliae (Metsch.) Sorok may suppress wild tsetse populations when autodisseminated from devices mounted on pyramidal traps [88]. Furthermore, horizontal transmission of the EPF was demonstrated between $M$. anisopliae-infected G. pallidipes and fungus-free flies during mating [89]. These characteristics make $M$. anisopliae a suitable candidate to be combined with SIT. Prior to causing death, 
fungal infection can significantly reduce tsetse feeding and reproduction [90-92]. Therefore, the complementary action of EPF on reducing tsetse's blood feeding and reproduction capacity, and potential effects on trypanosome development within the vector, could influence disease epidemiology and transmission. During the CRP, Wamiti et al. [93; this issue] conducted research focused on determining the impact of EPF on trypanosome infection. The results indicate that infection of G. $f$. fuscipes with $M$. anisopliae resulted not only in significant reduction in $T$. congolense titers, but also hindered the fly's vectorial competence (ability to acquire and transmit trypanosomes to mice). The precise mechanism(s) underlying the fungal-mediated anti-trypanosome impacts remain to be elucidated.

\section{Effects of irradiation on tsetse, its microbiota and trypanosome infections}

One of the major objectives of this CRP was to investigate the possibility of combining paratransgenesis with SIT to control tsetse population size and simultaneously reduce their vector competence. Paratransgenesis involves genetically modifying tsetse's commensal endosymbiont Sodalis so that it produces anti-trypanosome factors. Modified Sodalis are reintroduced into female flies, which subsequently present a trypanosome refractory phenotype ([94]; see section "Prospects of developi ng symbiont-based anti-trypanosome strategies" below for more details). As sterile males are produced via exposure to irradiation, the impact of this treatment on modified Sodalis is crucial for the implementation of the combined approach. To this end, Demirbaş-Uzel et al. [95; this issue] investigated the correlation between tsetse developmental stage (22- day old pupae, 29-day old pupae and 7-day old adults) at the time of radiation exposure and impact on Sodalis density. The results indicate that irradiation of seven-days old G. m. morsitans adults significantly reduced Sodalis densities. Furthermore, the recovery of Sodalis densities was significantly higher in the adults that emerged from puparia that had been irradiated on day 22 post larviposition as compared to the flies that had been irradiated as adults [95]. Results also indicate that irradiation of puparia on day 22 post larviposition has no effect on the vectorial capacity of the emerged males to transmit trypanosomes. The recovery of Sodalis titers in sterile males opens the door to combine paratransgenesis with SIT for tsetse control. In addition, pupal irradiation is operationally advantageous in terms of handling and transportation compared to adult irradiation [96].

Field released sterile males must efficiently identify and mate with wild females. Therefore, one component of the CRP investigated the effects of various doses of ionizing radiation on tsetse cuticular hydrocarbon (CHCs; e.g. n-alkanes, alkenes and methyl-branched hydrocarbons) profiles. CHCs act as sex pheromones for species, sex, and mate recognition in Drosophila [97] and tsetse [98]. Engl et al. [99; this issue] investigated the impact of bacterial symbionts and irradiation on tsetse $\mathrm{CHC}$ profiles. They discovered that antibiotic-mediated knockdown of tsetse's indigenous microbiota significantly reduced tsetse's $\mathrm{CHCs}$ profiles and correspondingly impacted mate choice. [99; this issue]. However, no significant differences in $\mathrm{CHC}$ profiles were observed between irradiated and non-irradiated G. $m$. morsitans flies [99]. These findings call for further research into the roles of microbiota (e.g. Wigglesworthia) in tsetse's mating behavior (in terms of $\mathrm{CHC}$ synthesis), and how the effects of irradiation on the microbiota can be reversed in irradiated males before inundative releases during SIT applications.

\section{Prospects of developing symbiont-based anti- trypanosome strategies}

The development of trypanosome-refractory sterile males would make SIT much less controversial, particularly when applied in trypanosome-endemic locations [20]. The viviparous reproduction of tsetse is not directly amenable to germ-line transformation for the purpose of ectopically expressing trypanocidal transgenes in an effort to reduce the fly's vector competence [100]. However, trypanosome-refractoriness can be indirectly conferred to tsetse via paratransgenesis, whereby genetically engineered symbionts express molecules that block trypanosome development and/or transmission [101] (Fig. 2). This approach works in triatome bugs [102] and mosquitoes [103, 104]. Sodalis is an ideal bacterium for expressing effector molecules in paratransgenic tsetse because it (i) resides in close proximity to trypanosomes; (ii) can be cultured and engineered in vitro; (iii) can be re-introduced into tsetse after transformations; (iv) is maternally transmitted to fly progenies, and (v) is rigorously restricted to the tsetse host niche [105]. Engineered Sodalis can express and release significant amounts of functional nanobodies that target trypanosome surface epitopes in different tsetse tissues $[94,106]$. Moreover, improved strategies have been developed to: (i) identify and determine population dynamics of tsetse species in a particular area [107; this issue], (ii) establish stable chromosomal expression in Sodalis allowing strong and constitutive expression of anti-trypanosome compounds [108], and (iii) sustainably colonize tsetse and its subsequent generations with genetically modified Sodalis through microinjection into third-instar larvae [109; this issue]. Sodalis-mediated inhibition of parasite development in paratransgenic tsetse remains to be demonstrated. 


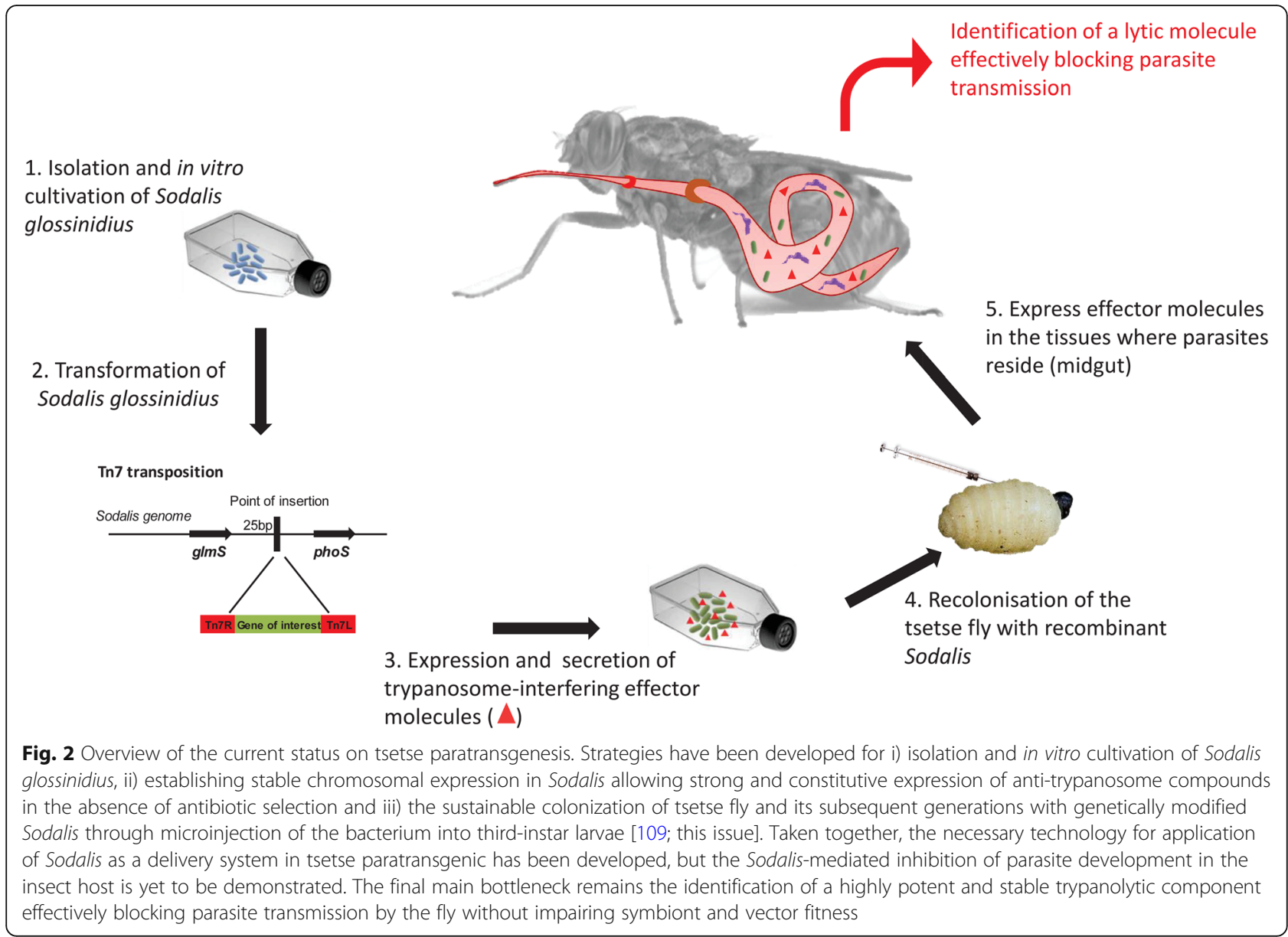

\section{Conclusions}

A large body of information related to enhancing tsetse fly refractoriness to trypanosome infections was acquired over the course of this CRP. However, many challenges and questions remain, which include, but are not limited to 1) developing more efficient tools to correctly classify field captured tsetse flies, 2) further deciphering the functional association between tsetse's microbiota (including environmentally acquired enteric bacteria, endosymbiotic microbes and pathogenic or symbiotic viruses and fungi) and the fly's physiology and trypanosome vector competency, 3) optimizing SIT irradiation protocols so that the treatment has a minimal effect of tsetse/endosymbiont fitness, and 4) maximizing the efficiency of tsetse paratransgenesis. Theoretical and technical knowledge acquired from experiments performed using the model tsetse species, G. m. morsitans (and its associated microorganisms), serves as a foundation for similar studies in other, more epidemiologically relevant tsetse species.

This CRP served as a platform for scientists from African, European and North American countries to interact, exchange ideas and develop long-term, mutually beneficial collaborations. Additionally, the extensive collaborations established during the CRP will continue in a new five-year CRP, which will address various issues related to the improvement of colony management in tsetse mass rearing for SIT applications (http:// www-naweb.iaea.org/nafa/ipc/crp/new-crps-ipc.html). Finally, African members of this CRP can disseminate knowledge and expertise acquired to additional research communities in other tsetse-endemic regions of sub-Saharan Africa and to national authorities to promote the novel insights in tsetse and trypanosomosis control.

\footnotetext{
Abbreviations

16S rRNA: 165 ribosomal RNA; 5'-Nuc: 5'-nucleotidase-related saliva protein; ADA: Adenine deaminase; Ago: Argonaute; AMP: Antimicrobial peptide; ArgK: Arginine kinase; AW-IPM: Area-wide integrated pest management; BSF: Bloodstream form; CaMK: Ca2+/calmodulin-dependent protein kinase; CHCs: Cuticular hydrocarbons; Cl: Cytoplasmic incompatibility; CRP: Coordinated research project; Dcr: Dicer; DEG: Differentially expressed gene; DENV: Dengue virus; dsRNA: Double-stranded RNA; EPF: Entomopathogenic fungus; FAO: Food and Agricultural Organization of the United Nations; GpSGHV: Glossina pallidipes salivary gland hypertrophy virus; HGT: Horizontal gene transfer; IAEA: International Atomic Energy Agency; Imd: Immune deficiency; MdSGHV: Musca domestica salivary gland hypertrophy virus; miRNA: Micro RNA;
} 
MLST: Multi locus sequence typing; MT parasites: Mammalian-infective metacyclic parasites; PGRP-LB: Peptidoglycan-recognition protein LB; piRNA: Piwi-interacting RNA; RCM: Research Coordination Meetings; RNAi: RNA interference; RNA-Seq: Ribonucleic acid (RNA) sequencing; ROS: Reactive oxygen species; SG: Salivary gland; siRNA: Short interfering RNA; SIT: Sterile insect technique; Spg3: 5'-nucleotidase-related SG protein-3; TAg5: Salivary antigen-5-protein; Tbb: Trypanosoma brucei brucei; Tbg: Trypanosoma brucei gambiense; Tbr: Trypanosoma brucei rhodesiense; Tc: Trypanosoma congolense; Tsal1/2: Tsetse salivary gland proteins 1 \& 2; TSGF-1/2: Tsetse salivary growth factors $1 \& 2 ; \mathrm{V}$ ATPase: Vacuolar-type $\mathrm{H}^{+}$-ATPase

\section{Acknowledgements}

We thank Dr. Geoffrey M. Attardo from the University of California, Davis, for his kind effort in preparing Fig. 1. This work was funded by the Joint FAO/ IAEA Division of Nuclear Techniques in Food and Agriculture, Vienna, Austria (Coordinate Research Project No. D42015). Meki IK is a recipient of a sandwich PhD grant from Wageningen University. All the colleagues who participated in the CRP and contributed to the review of the articles in this Special Issue are cordially acknowledged.

\section{Funding}

This work and the publication was funded by the Joint FAO/IAEA Division of Nuclear Techniques in Food and Agriculture, IAEA (CRP No.: D4.20.15) Vienna, Austria.

\section{About this supplement}

This article has been published as part of BMC Microbiology Volume 18 Supplement 1, 2018: Enhancing Vector Refractoriness to Trypanosome Infection. The full contents of the supplement are available online at https://bmcmicrobiol.biomedcentral.com/articles/supplements/volume-18supplement-1.

\section{Authors' contributions}

$H K, I M, D S, D L, F K, A G$ and GD-U wrote the first draft of the manuscript. HK and AA coordinated the writing of the manuscript. JV, Al, SK, FN, FW, MI, and BW contributed to manuscript writing. All authors read and approved the final version of the manuscript.

\section{Ethics approval and consent to participate}

Not applicable

\section{Consent for publication}

Not applicable

\section{Competing interests}

The authors declare that they have no competing interests.

\section{Publisher's Note}

Springer Nature remains neutral with regard to jurisdictional claims in published maps and institutional affiliations.

\section{Author details}

'Biotechnology Research Institute, Kenya Agricultural \& Livestock Research Organization, P.O Box 57811, 00200, Kaptagat Rd, Loresho, Nairobi, Kenya. ${ }^{2}$ Molecular Department, Vector and Vector Borne Diseases Institute, Tanzania Veterinary Laboratory Agency, Majani Mapana, Off Korogwe Road, Box, 1026 Tanga, Tanzania. ${ }^{3}$ Insect Pest Control Laboratory, FAO/IAEA Agriculture \& Biotechnology Laboratory, IAEA Laboratories Seibersdorf, A-2444 Seibersdorf, Austria. ${ }^{4}$ Laboratory of Virology, Wageningen University and Research, Wageningen 6708 PB, The Netherlands. ${ }^{5}$ Department of Epidemiology of Microbial Diseases, Yale School of Public Health, 60 College Street, New Haven, CT 06510, USA. ${ }^{6}$ Department of Biomedical Sciences, Institute of Tropical Medicine, Antwerp, Belgium. ${ }^{7}$ International Centre of Insect Physiology and Ecology, P.O. Box 30772, 00100, Nairobi, Kenya. ${ }^{8}$ INTERTRYP, Institut de Recherche pour le Développement, University of Montpellier, Montpellier, France. ${ }^{9}$ Institute of Chemical, Environmental \& Biological Engineering, Research Area Biochemical Technology, Vienna University of Technology, Gumpendorfer Straße 1a, 1060 Vienna, Austria. ${ }^{10}$ Department of Medical Microbiology, Acıbadem Mehmet Ali Aydınlar University, School of Medicine, 34752, Ataşehir, Istanbul, Turkey. ${ }^{11}$ Centre for Biomolecular
Interactions Bremen, Faculty for Biology \& Chemistry, Universität Bremen, Bibliothekstraße 1, 28359 Bremen, Germany. ${ }^{12}$ Laboratory of Parasitology and Ecology, Faculty of Sciences, Department of Animal Biology and Physiology, University of Yaoundé 1, Yaoundé, BP 812, Cameroon. ${ }^{13}$ Trypanosomiasis Research Centre, Kenya Agricultural \& Livestock Research Organization, P.O. Box 362-00902, Kikuyu, Kenya.

Published: 23 November 2018

\section{References}

1. Mattioli RC, Feldmann U, Hendrickx G, Wint W, Jannin J, Slingenbergh J. Tsetse and trypanosomiasis intervention policies supporting sustainable animal-agricultural development. J Food Agric Environ. 2004;2:310-4.

2. Cecchi G, Mattioli RC, Slingenbergh J, De La Rocque S. Land cover and tsetse fly distributions in sub-Saharan Africa. Med Vet Entomol. 2008;22: 364-73.

3. Barrett MP, Vincent IM, Burchmore RJ, Kazibwe AJ, Matovu E. Drug resistance in human African trypanosomiasis. Future Microbiol. 2011;6: 1037-47.

4. Geerts S, Holmes PH, Eisler MC, Diall O. African bovine trypanosomiasis: the problem of drug resistance. Trends Parasitol. 2001;17:25-8.

5. Schofield CJ, Kabayo JP. Trypanosomiasis vector control in Africa and Latin America. Parasit Vectors. 2008;1:24.

6. Vreysen MJ. Prospects for area-wide integrated control of tsetse flies (Diptera: Glossinidae) and trypanosomosis in sub-Saharan Africa. Rev Soc Entomológica Argent. 2006:65:1-21.

7. Vreysen MJ, Saleh K, Mramba F, Parker A, Feldmann U, Dyck VA, et al. Sterile insects to enhance agricultural development: the case of sustainable tsetse eradication on Unguja Island, Zanzibar, using an area-wide integrated pest management approach. PLoS Negl Trop Dis. 2014;8:e2857.

8. Vreysen MJB. Principles of area-wide integrated tsetse fly control using the sterile insect technique. Méd Trop. 2001;61:397-411.

9. Vreysen MJB, Saleh KM, Lancelot R, Bouyer J. Factory tsetse flies must behave like wild flies: a prerequisite for the sterile insect technique. PLoS Negl Trop Dis. 2011;5:e907.

10. Molyneux DH, Hopkins DR, Zagaria N. Disease eradication, elimination and control: the need for accurate and consistent usage. Trends Parasitol. 2004; 20:347-51.

11. Olandunmade MA, Feldmann U, Takken W, Tenabe SO, Hamann HJ, Onah J, et al. Eradication of Glossina palpalis palpalis (Robineau-Desvoidy) (Diptera: Glossinidae) from agropastoral land in Central Nigeria by means of the sterile insect technique. In: Offori ED, Van de Vloedt AMV, editors. Sterile insect technique for tsetse control and eradication. Vienna: International Atomic Energy Agency; 1990. p. 5-23.

12. Politzar H, Merot P, Brandl FE. Experimental aerial release of sterile males of Glossina palpalis gambiensis and of Glossina tachinoides in a biological control operation. Rev D'élevage Méd Vét Pays Trop. 1984;37:198-202.

13. Kebede A, Ashenafi H, Daya T. A review on sterile insect technique (SIT) and its potential towards tsetse eradication in Ethiopia. Adv Life Sci Technol. 2015;37:24-44.

14. Enserink M. Welcome to Ethiopia's fly factory. Science. 2007;317:310.

15. Abd-Alla AMM, Kariithi HM, Mohamed AH, Lapiz E, Parker AG, Vreysen MJB. Managing hytrosavirus infections in Glossina pallidipes colonies: feeding regime affects the prevalence of salivary gland hypertrophy syndrome. PLoS One. 2013;8:e61875

16. Kariithi HM, van Oers MM, Vlak JM, Vreysen MJ, Parker AG, Abd-Alla AM. Virology, epidemiology and pathology of Glossina hytrosavirus, and its control prospects in laboratory colonies of the tsetse fly, Glossina pallidipes (Diptera; Glossinidae). Insects. 2013;4:287-319.

17. Terblanche JS, Chown SL. Factory flies are not equal to wild flies. Science. 2007:317:1678.

18. Lauzon CR, Potter SE. Description of the irradiated and nonirradiated midgut of Ceratitis capitata Wiedemann (Diptera: Tephritidae) and Anastrepha ludens Loew (Diptera: Tephritidae) used for sterile insect technique. JPest Sci. 2012;85:217-26.

19. Engel $P$, Moran NA. The gut microbiota of insects: diversity in structure and function. FEMS Microbiol Rev. 2013;37:699-735.

20. Abbeele VDJ, Bourtzis K, Weiss B, Cordón-Rosales C, Miller W, Abd-Alla AMM et al. Enhancing tsetse fly refractoriness to trypanosome infection: a new IAEA coordinated research project. J Invertebr Pathol. 2013;112:S142-7. 
21. Augustinos A, Meki IK, Demirbas-Uzel G, Ouedraogo GMS, Saridaki A, Tsiamis G, et al. Nuclear and Wolbachia-based multimarker approach for the rapid and accurate. BMC Microbiol. 2018. https://doi.org/10.1186/s12866-018-1295-4.

22. Morlais I, Grebaut P, Bodo JM, Djoha S, Cuny G, Herder S. Detection and identification of trypanosomes by polymerase chain reaction in wild tsetse flies in Cameroon. Acta Trop. 1998;70:109-17.

23. Simo G, Njitchouang GR, Njiokou F, Cuny G, Asonganyi T. Trypanosoma brucei s.l.: microsatellite markers revealed high level of multiple genotypes in the mid-guts of wild tsetse flies of the Fontem sleeping sickness focus of Cameroon. Exp Parasitol. 2011;128:272-8.

24. Farikou O, Njiokou F, Mbida Mbida JA, Njitchouang GR, Djeunga HN, Asonganyi T, et al. Tripartite interactions between tsetse flies, Sodalis glossinidius and trypanosomes - an epidemiological approach in two historical human African trypanosomiasis foci in Cameroon. Infect Genet Evol. 2010;10:115-21.

25. Simo G, Fongho P, Farikou O, Ndjeuto-Tchouli PIN, Tchouomene-Labou J, Njiokou F, et al. Trypanosome infection rates in tsetse flies in the "silent" sleeping sickness focus of Bafia in the Centre region in Cameroon. Parasit Vectors. 2015;8:528.

26. Kame-Ngasse G, Njiokou F, Melachio-Tanekou TT, Farikou O, Simo G, Geiger A. Prevalence of symbionts and trypanosome infections in tsetse flies of two villages of the "Faro and Déo" division of the Adamawa Region of Cameroon. BMC Microbiol. 2018; https://doi.org/10.1186/s12866-018-1286-5.

27. Simo G, Silatsa B, Flobert N, Lutumba P, Mansinsa P, Madinga J, et al. Identification of different trypanosome species in the mid-guts of tsetse flies of the Malanga (Kimpese) sleeping sickness focus of the Democratic Republic of Congo. Parasit Vectors. 2012;5:201.

28. Ouedraogo GMS, Demirbaş-Uzel G, Rayaisse J-B, Traore A, Augustinos AA, Parker AG, et al. Prevalence of trypanosomes, salivary gland hypertrophy virus and Wolbachia in wild populations of tsetse flies from West Africa. BMC Microbiol. 2018; https://doi.org/10.1186/s12866-018-1287-4.

29. Njiokou F, Simo G, Nkinin S, Laveissière C, Herder S. Infection rate of Trypanosoma brucei sl, T. vivax, T. congolense "forest type", and T. simiae in small wild vertebrates in South Cameroon. Acta Trop. 2004;92:139-46.

30. Simo G, Njiokou F, Mbida JM, Njitchouang G, Herder S, Asonganyi T, et al. Tsetse fly host preference from sleeping sickness foci in Cameroon: epidemiological implications. Infect Genet Evol. 2008:8:34-9.

31. Njiokou F, Simo G, Mbida Mbida A, Truc P, Cuny G, Herder S. A study of host preference in tsetse flies using a modified heteroduplex PCR-based method. Acta Trop. 2004;91:117-20

32. Nimpaye $H$, Njiokou F, Njine T, Njitchouang G, Cuny G, Herder S, et al. Trypanosoma vivax, T. congolense "forest type" and T. simiae: prevalence in domestic animals of sleeping sickness foci of Cameroon. Parasite. 2011;18:171.

33. Kariithi HM, Boeren S, Murungi EK, Vlak JM, Abd-Alla AMM. A proteomics approach reveals molecular manipulators of distinct cellular processes in the salivary glands of Glossina m. morsitans in response to Trypanosoma b. brucei infections. Parasit Vectors. 2016:9:424.

34. Van Den Abbeele J, Caljon G, De Ridder K, De Baetselier P, Coosemans M. Trypanosoma brucei modifies the tsetse salivary composition, altering the fly feeding behavior that favors parasite transmission. PLoS Pathog. 2010;6:e1000926.

35. Peacock L, Ferris V, Bailey M, Gibson W. The influence of sex and fly species on the development of trypanosomes in tsetse flies. PLoS Negl Trop Dis. 2012;6:e1515.

36. Bateta R, Wang J, Wu Y, Weiss BL, Warren WC, Murilla GA, et al. Tsetse fly (Glossina pallidipes) midgut responses to Trypanosoma brucei challenge. Parasit Vectors. 2017;10:614.

37. Aksoy E, Vigneron A, Bing X, Zhao X, O'Neill M, Wu Y, et al. Mammalian African trypanosome VSG coat enhances tsetse's vector competence. Proc Natl Acad Sci. 2016;113:6961-6.

38. Maudlin I, Ellis DS. Association between intracellular rickettsial-like infections of midgut cells and susceptibility to trypanosome infection in Glossina spp. Z Für Parasitenkd. 1985;71:683-7.

39. Welburn SC, Maudlin I. Tsetse-trypanosome interactions: rites of passage. Parasitol Today. 1999;15:399-403.

40. Dale C, Welburn S. The endosymbionts of tsetse flies: manipulating hostparasite interactions. Int J Parasitol. 2001;31:628-31.

41. Geiger A, Ravel S, Mateille T, Janelle J, Patrel D, Cuny G, et al. Vector competence of Glossina palpalis gambiensis for Trypanosoma brucei s.l. and genetic diversity of the symbiont Sodalis glossinidius. Mol Biol Evol. 2006;24: 102-9.
42. Hamidou Soumana I, Loriod B, Ravel S, Tchicaya B, Simo G, Rihet P, et al. The transcriptional signatures of Sodalis glossinidius in the Glossina palpalis gambiensis flies negative for Trypanosoma brucei gambiense contrast with those of this symbiont in tsetse flies positive for the parasite: possible involvement of a Sodalis-hosted prophage in fly Trypanosoma-refractoriness? Infect Genet Evol. 2014;24:41-56.

43. Channumsin M, Ciosi M, Masiga D, Turner CMR, Mable BK. Sodalis glossinidius presence in wild tsetse is only associated with presence of trypanosomes in complex interactions with other tsetse-specific factors BMC Microbiol. 2018; https://doi.org/10.1186/s12866-018-1285-6.

44. Griffith BC, Weiss BL, Aksoy E, Mireji PO, Auma JE, Wamwiri FN, et al. Analysis of the gut-specific microbiome from field-captured tsetse flies, and its relevance to host trypanosome vector competence. BMC Microbiol. 2018; https://doi.org/10.1186/s12866-018-1284-7.

45. Klepzig KD, Adams AS, Handelsman J, Raffa KF. Symbioses: a key driver of insect physiological processes, ecological interactions, evolutionary diversification, and impacts on humans. Environ Entomol. 2009:38:67-77.

46. Wang J, Weiss BL, Aksoy S. Tsetse fly microbiota: form and function. Front Cell Infect Microbiol. 2013;3:6 pages.

47. Bing X, Attardo GM, Vigneron A, Aksoy E, Scolari F, Malacrida A, et al. Unravelling the relationship between the tsetse fly and its obligate symbiont Wigglesworthia: transcriptomic and metabolomic landscapes reveal highly integrated physiological networks. Proc R Soc B Biol Sci. 2017; 284:20170360

48. Benoit JB, Vigneron A, Broderick NA, Wu Y, Sun JS, Carlson JR, et al. Symbiont-induced odorant binding proteins mediate insect host hematopoiesis. elife. 2017;6:e19535.

49. Geiger A, Fardeau ML, Falsen E, Ollivier B, Cuny G. Serratia glossinae sp. nov., isolated from the midgut of the tsetse fly Glossina palpalis gambiensis. Int J Syst Evol Microbiol. 2010;60:1261-5.

50. Geiger A, Fardeau ML, Grebaut P, Vatunga G, Josenando T, Herder S, et al. First isolation of Enterobacter, Enterococcus, and Acinetobacter spp. as inhabitants of the tsetse fly (Glossina palpalis papalis) midgut. Infect Genet Evol. 2009;9:1364-70.

51. Geiger A, Fardeau ML, Njiokou F, Joseph M, Asonganyi T, Ollivier B, et al. Bacterial diversity associated with populations of Glossina spp. from Cameroon and distribution within the campo sleeping sickness focus. Microb Ecol. 2011;62:632-43.

52. Lindh JM, Lehane MJ. The tsetse fly Glossina fuscipes fuscipes (Diptera: Glossina) harbors a surprising diversity of bacteria other than symbionts. Antonie Van Leeuwenhoek. 2011;99:711-20.

53. Aksoy E, Telleria EL, Echodu R, Wu Y, Okedi LM, Weiss BL, et al. Analysis of multiple tsetse fly populations in Uganda reveals limited diversity and species-specific gut microbiota. Appl Environ Microbiol. 2014;80: 4301-12.

54. Malele I, Nyingilili HH, Lyaruu EA, Tauzin M, Ollivier B, Fardeau ML, et al. Bacterial diversity obtained by culturable approaches in the gut of Glossina pallidipes population from a non sleeping sickness focus in Tanzania: preliminary results BMC Microbiol. 2018; https://doi.org/10.1186/s12866018-1288-3.

55. Colman DR, Toolson EC, Takacs-Vesbach CD. Do diet and taxonomy influence insect gut bacterial communities? Mol Ecol. 2012;21:5124-37.

56. Poinar GOJ, Wassink HJ. Leegwater-van der Linden ME, van der Geest LP. Serratia marcescens as a pathogen of tsetse flies. Acta Trop. 1979;36:223-7.

57. Bahia AC, Dong Y, Blumberg BJ, Mlambo G, Tripathi A, BenMarzouk-Hidalgo OJ, et al. Exploring Anopheles gut bacteria for Plasmodium-blocking activity: anti-Plasmodium microbes. Environ Microbiol. 2014;16:2980-94.

58. Doudoumis V, Blow F, Saridaki A, Augustinos A, Dyer NA, Goodhead I, et al. Challenging the Wigglesworthia, Sodalis, Wolbachia symbiosis dogma in tsetse flies: Spiroplasma is present in both laboratory and natural populations. Sci Rep. 2017;7:4699 Article number.

59. Jacob F, Melachio TT, Njitchouang GR, Gimonneau G, Njiokou F, Abate L, et al. Intestinal bacterial communities of trypanosome-infected and uninfected Glossina palpalis palpalis from three human African trypanomiasis foci in Cameroon. Front Microbiol. 2017;8:1464.

60. Herren JK, Paredes JC, Schupfer F, Lemaitre B. Vertical transmission of a Drosophila endosymbiont via cooption of the yolk transport and internalization machinery. mBio. 2013;4:e00532-12-e00532 12

61. Chepkemoi ST, Mararo E, Butungi H, Paredes J, Masiga D, Sinkins SP, et al. Identification of Spiroplasma insolitum symbionts in Anopheles gambiae. Wellcome Open Res. 2017;2:90. 
62. Oliver KM, Smith AH, Russell JA. Defensive symbiosis in the real world advancing ecological studies of heritable, protective bacteria in aphids and beyond. Funct Ecol. 2014;28:341-55.

63. Jaenike J, Unckless R, Cockburn S, Boelio L, Perlman S. Adaptation via symbiosis: recent spread of a Drosophila defensive symbiont. Science. 2010; 329:212-5.

64. Shokal U, Yadav S, Atri J, Accetta J, Kenney E, Banks K, et al. Effects of cooccurring Wolbachia and Spiroplasma endosymbionts on the Drosophila immune response against insect pathogenic and non-pathogenic bacteria. BMC Microbiol. 2016:16:16.

65. Ratzka C, Gross R, Feldhaar H. Endosymbiont tolerance and control within insect hosts. Insects. 2012;3:553-72.

66. Telschow A, Flor M, Kobayashi Y, Hammerstein P, Werren JH. Wolbachiainduced unidirectional cytoplasmic incompatibility and speciation: mainland-island model. PLoS One. 2007:2:e701.

67. Brucker RM, Bordenstein SR. The hologenomic basis of speciation: gut bacteria cause hybrid lethality in the genus Nasonia. Science. 2013;341:667-9.

68. Brucker RM, Bordenstein SR. Speciation by symbiosis. Trends Ecol Evol. 2012; 27:443-51

69. Telschow A, Hilgenboecker K, Hammerstein P, Werren JH. DobzhanskyMuller and Wolbachia-induced incompatibilities in a diploid genetic system. PLoS One. 2014;9:e95488.

70. Alam U, Medlock J, Brelsfoard C, Pais R, Lohs C, Balmand S, et al. Wolbachia symbiont infections induce strong cytoplasmic incompatibility in the tsetse fly Glossina morsitans. PLoS Pathog. 2011;7:e1002415.

71. Schneider DI, Garschall KI, Parker AG, Abd-Alla AMM, Miller WJ. Global Wolbachia prevalence, titer fluctuations and their potential of causing cytoplasmic incompatibilities in tsetse flies and hybrids of Glossina morsitans subgroup species. J Invertebr Pathol. 2013;112:S104-15.

72. Schneider DI, Parker AG, AMM A-A, Miller WJ. High-sensitivity detection of cryptic Wolbachia in the African tsetse fly (Glossina spp.). BMC Microbiol. 2018; https://doi.org/10.1186/s12866-018-1291-8.

73. Gooding $\mathrm{RH}$. Postmating barriers to gene flow among species and subspecies of tsetse flies (Diptera: Glossinidae). Can J Zool. 1990;68:1727-34

74. Gooding R. Genetics of sterility among Glossina morsitans sspp and G. swynnertoni hybrids. Zanzibar: United Republic of Tanzania: Backhuys Publishers; 1999. p. 99-109.

75. Abd-Alla AM, Marin C, Parker AG, Vreysen MJ. Antiviral drug valacyclovir treatment combined with a clean feeding system enhances the suppression of salivary gland hypertrophy in laboratory colonies of Glossina pallidipes. Parasit Vectors. 2014;7:214

76. Abd-Alla AM, Kariithi HM, Cousserans F, Parker NJ, Ince IA, Scully ED, et al. Comprehensive annotation of Glossina pallidipes salivary gland hypertrophy virus from Ethiopian tsetse flies: a proteogenomics approach. J Gen Virol. 2016;97:1010-31.

77. Demirbaş-Uzel G, Kariithi HM, Parker AG, Vreysen MJB, Mach RL, Abd-Alla AMM. Susceptibility of tsetse species to Glossina pallidipes salivary gland hypertrophy virus (GpSGHV). Front Microbiol. 2018;9. https://doi.org/10. 3389/fmicb.2018.00701.

78. Kariithi HM, Boucias DG, Murungi EK, Meki IK, Demirbaş-Uzel G, van Oers $\mathrm{MM}$, et al. Coevolution of hytrosaviruses and host immune responses. BMC Microbiol. 2018; https://doi.org/10.1186/s12866-018-1296-3.

79. Kariithi HM, Ince Al, Boeren S, Murungi EK, Meki IK, Otieno EA, et al. Comparative analysis of salivary gland proteomes of two Glossina species that exhibit differential hytrosavirus pathologies. Front Microbiol. 2016:7:89.

80. Meki IK, Kariithi HM, Ahmadi M, Parker AG, Vreysen MJB, Vlak JM, et al. Hytrosavirus genetic diversity and eco-regional spread in Glossina species. BMC Microbiol. 2018; https://doi.org/10.1186/s12866-018-1297-2.

81. Demirbaş-Uzel G, Parker AG, Vreysen MJB, Mach RL, Bouyer J, Takac P, et al. Impact of Glossina pallidipes salivary gland hypertrophy virus (GpSGHV) on a heterologous tsetse fly host, Glossina fuscipes fuscipes. BMC Microbiol. 2018; https://doi.org/10.1186/s12866-018-1276-7.

82. Kariithi HM, Meki IK, Boucias DG, Abd-Alla AM. Hytrosaviruses: current status and perspective. Curr Opin Insect Sci. 2017:22:71-8.

83. Meki IK, Kariithi HM, Parker AG, Vreysen MJB, Ros VID, Vlak JM, et al. RNA interference-based antiviral immune response against the salivary gland hypertrophy virus in Glossina pallidipes. BMC Microbiol. 2018; https://doi.org/10.1186/s12866-018-1298-1.

84. Meki IK, Ikbal Al, Kariithi HM, Parker AG, MJB V, Vlak JM, et al. Expression profile of $G$. pallidipes miRNA during infection by the Glossina pallidipes salivary gland hypertrophy virus. Prep. 2018.
85. Zhang G, Hussain M, O'Neill SL, Asgari S. Wolbachia uses a host microRNA to regulate transcripts of a methyltransferase, contributing to denque virus inhibition in Aedes aegypti. Proc Natl Acad Sci. 2013;110:10276-81.

86. Boucias DG, Kariithi HM, Bourtzis K, Schneider DI, Kelley K, Miller WJ, et al. Trans-generational transmission of the Glossina pallidipes hytrosavirus depends on the presence of a functional symbiome. PLoS One. 2013;8:e61150.

87. Scholte E-J, Knols BG, Samson RA, Takken W. Entomopathogenic fungi for mosquito control: a review. J Insect Sci. 2004:4:19.

88. Maniania NK, Ekesi S, Odulaja A, Okech MA, Nadel DJ. Prospects of a fungus-contamination device for the control of tsetse fly Glossina fuscipes fuscipes. Biocontrol Sci Tech. 2006;16:129-39.

89. Maniania NK, Ekesi S. The use of entomopathogenic fungi in the control of tsetse flies. J Invertebr Pathol. 2013:112:S83-8.

90. Maniania NK, Ekesi S, Songa JM. Managing termites in maize with the entomopathogenic fungus Metarhizium anisopliae. Insect Sci Its Appl. 2002; 22:41-6.

91. McQuilken MP, Halmer P, Rhodes DJ. Application of microorganisms to seeds. In: Burges HD, editor. Formulation of microbial biopesticides: beneficial microorganisms, nematodes and seed treatments. 1st ed. Dordrecht: Kluwer Academic Publisher; 1998. p. 255-85.

92. Hajek AE, St. Leger RJ. Interactions between fungal pathogens and insect hosts. Annu Rev Entomol. 1994;39:293-322.

93. Wamiti LG, Khamis FM, Abd-Alla AMM, Ombura FLO, Akutse KS, Subramanian $\mathrm{S}$, et al. Metarhizium anisopliae infection reduces Trypanosoma congolense reproduction in Glossina fuscipes fuscipes and its ability to acquire or transmit the parasite. BMC Microbiol. 2018; https://doi.org/10.1186/s12866-018-1277-6.

94. De Vooght L, Caljon G, De Ridder K, Van Den Abbeele J. Delivery of a functional anti-trypanosome nanobody in different tsetse fly tissues via a bacterial symbiont Sodalis glossinidius. Microb Cell Factories. 2014;13:156.

95. Demirbaş-Uzel G, Parker AG, De Vooght L, Abbeele JVD, Vreysen MJB, AbdAlla AMM. Combining paratransgenesis with SIT: impact of ionizing radiation on the DNA copy number of Sodalis glossinidius in tsetse flies. BMC Microbiol. 2018; https://doi.org/10.1186/s12866-018-1283-8.

96. de Beer CJ, Moyaba P, Boikanyo SNB, Majatladi D, Yamada H, Venter GJ, et al. Evaluation of radiation sensitivity and mating performance of Glossina brevipalpis males. PLoS Negl Trop Dis. 2017:11:e0005473.

97. Everaerts C, Farine J-P, Cobb M, Ferveur J-F. Drosophila cuticular hydrocarbons revisited: mating status alters cuticular profiles. PLoS One. 2010;5:e9607.

98. Carlson DA, Mramba F, Sutton BD, Bernier UR, Geden CJ. Sex pheromone of the tsetse species, Glossina austeni: isolation and identification of natural hydrocarbons, and bioassay of synthesized compounds. Med Vet Entomol. 2005;19:470-9.

99. Engl T, Michalkova V, Weiss BL, Demirbaş-Uzel G, Takac P, Miller WJ, et al. Effect of antibiotic treatment and gamma-irradiation on cuticular hydrocarbon profiles and mate choice in tsetse flies (Glossina M. morsitans). BMC Microbiol. 2018; https://doi.org/10.1186/s12866-018-1292-7.

100. Coutinho-Abreu IV, Zhu KY, Ramalho-Ortigao M. Transgenesis and paratransgenesis to control insect-borne diseases: current status and future challenges. Parasitol Int. 2010;59:1-8.

101. Wilke ABB, Marrelli MT. Paratransgenesis: a promising new strategy for mosquito vector control. Parasit Vectors. 2015;8:342.

102. Durvasula RV, Gumbs A, Panackal A, Kruglov O, Aksoy S, Merrifield RB, et al. Prevention of insect-borne disease: an approach using transgenic symbiotic bacteria. Proc Natl Acad Sci. 1997:94:3274-8.

103. Wang S, Ghosh AK, Bongio N, Stebbings KA, Lampe DJ, Jacobs-Lorena M. Fighting malaria with engineered symbiotic bacteria from vector mosquitoes. Proc Natl Acad Sci. 2012;109:12734-9.

104. Bongio NJ, Lampe DJ. Inhibition of Plasmodium berghei development in mosquitoes by effector proteins secreted from Asaia sp bacteria using a novel native secretion signal. PLOS ONE. 2015;10:e0143541.

105. Medlock J, Atkins KE, Thomas DN, Aksoy S, Galvani AP. Evaluating paratransgenesis as a potential control strategy for African trypanosomiasis. PLoS Negl Trop Dis. 2013;7:e2374.

106. De Vooght L, Caljon G, Stijlemans B, De Baetselier P, Coosemans M, Van Den Abbeele J. Expression and extracellular release of a functional antitrypanosome Nanobody ${ }^{\oplus}$ in Sodalis glossinidius, a bacterial symbiont of the tsetse fly. Microb Cell Factories. 2012;11:23.

107. Shaida SS, Weber JS, Gbem TT, Ngomtcho CSH, Musa UB, Achukwi MD, et al. Diversity and phylogenetic relationships of Glossina populations in Nigeria. BMC Microbiol. 2018; https://doi.org/10.1186/s12866-018-1293-6. 
108. De Vooght L, Caljon G, Van Hees J, Van Den Abbeele J. Paternal transmission of a secondary symbiont during mating in the viviparous tsetse fly. Mol Biol Evol. 2015;32:1977-80.

109. De Vooght L, Van Keer S, Van Den Abbeele J. Towards improving tsetse fly paratransgenesis: stable colonization of Glossina morsitans morsitans with genetically modified Sodalis. BMC Microbiol. 2018; https://doi.org/10.1186/s12866-018-1282-9.

110. Isaac C, Ciosi M, Hamilton A, Scullion KM, Dede P, Igbinosa IB, et al. Molecular identification of different trypanosome species and subspecies in tsetse flies of northern Nigeria. Parasit Vectors. 2016;9:301.

111. Abbeele JVD, Rotureau B. New insights in the interactions between African trypanosomes and tsetse flies. Front Cell Infect Microbiol. 2013;3:63.

112. International Glossina Genome Initiative, Attardo GM, Abila PP, Auma JE, Baumann AA, Benoit JB, et al. Genome sequence of the tsetse fly (Glossina morsitans): vector of African trypanosomiasis. Science. 2014;344:380-6.

113. Adam Y, Bouyer J, Dayo G-K, Mahama Cl, Vreysen MJB, Cecchi G, et al. Genetic comparison of Glossina tachinoides populations in three river basins of the upper west region of Ghana and implications for tsetse control. Infect Genet Evol. 2014;28:588-95.

114. Aksoy S, Attardo G, Berriman M, Christoffels A, Lehane M, Masiga D, et al. Human African trypanosomiasis research gets a boost: unraveling the tsetse genome. PLoS Negl Trop Dis. 2014;8:e2624.

115. Aksoy S, Buscher P, Lehane M, Solano P, Van Den Abbeele J. Human African trypanosomiasis control: achievements and challenges. PLoS Negl Trop Dis. 2017;11:e0005454.

116. Aksoy S, Weiss BL, Attardo GM. Trypanosome transmission dynamics in tsetse. Curr Opin Insect Sci. 2014;3:43-9.

117. Alves-e-Silva TL, Savage AF, Aksoy S. Transcript abundance of putative lipid phosphate phosphatases during development of Trypanosoma brucei in the tsetse fly. Am J Trop Med Hyg. 2016:94:890-3.

118. Awuoche EO, Weiss BL, Vigneron A, Mireji PO, Aksoy E, Nyambega B, et al. Molecular characterization of tsetse's proboscis and its response to Trypanosoma congolense infection. PLoS Negl Trop Dis. 2017;11:e0006057.

119. Benoit JB, Attardo GM, Baumann AA, Michalkova V, Aksoy S. Adenotrophic viviparity in tsetse flies: potential for population control and as an insect model for lactation. Annu Rev Entomol. 2015;60:351-71.

120. Benoit JB, Attardo GM, Michalkova V, Krause TB, Bohova J, Zhang Q, et al. A novel highly divergent protein family identified from a viviparous insect by RNA-seq analysis: a potential target for tsetse fly-specific abortifacients. PLoS Genet. 2014;10:e1003874.

121. Benoit JB, Hansen IA, Attardo GM, Michalková V, Mireji PO, Bargul JL, et al. Aquaporins are critical for provision of water during lactation and intrauterine progeny hydration to maintain tsetse fly reproductive success. PLoS Negl Trop Dis. 2014;8:e2517.

122. Beschin A, Van Den Abbeele J, De Baetselier P, Pays E. African trypanosome control in the insect vector and mammalian host. Trends Parasitol. 2014;30: $538-47$.

123. Ciosi M, Masiga DK, Turner CMR. Laboratory colonisation and genetic bottlenecks in the tsetse fly Glossina pallidipes. PLoS Negl Trop Dis. 2014:8:e2697

124. Geiger A, Bossard G, Sereno D, Pissarra J, Lemesre J-L, Vincendeau P, et al. Escaping deleterious immune response in their hosts: lessons from trypanosomatids. Front Immunol. 2016;7:212.

125. Geiger A, Hamidou Soumana I, Tchicaya B, Rofidal V, Decourcelle M, Santoni $\checkmark$, et al. Differential expression of midgut proteins in Trypanosoma brucei gambiense-stimulated vs non-stimulated Glossina palpalis gambiensis flies. Front Microbiol. 2015;6:444

126. Gitonga PK, Ndung'u K, Murilla GA, Thande PC, Wamwiri FN, Auma JE, et al. Differential virulence and tsetse fly transmissibility of Trypanosoma congolense and Trypanosoma brucei strains. Onderstepoort J Vet Res. 2017; 84:e1-10.

127. Gloria-Soria A, Dunn WA, Telleria EL, Evans BR, Okedi L, Echodu R, et al. Patterns of genome-wide variation in Glossina fuscipes fuscipes tsetse flies from Uganda. G3 Genes Genomes Genet. 2016;6:1573-84.

128. Hamidou Soumana I, Klopp C, Ravel S, Nabihoudine I, Tchicaya B, Parrinello $H$, et al. RNA-seq de novo assembly reveals differential gene expression in Glossina palpalis gambiensis infected with Trypanosoma brucei gambiense vs non-infected and self-cured flies. Front Microbiol. 2015;6:1259.

129. Hamidou Soumana I, Tchicaya B, Chuchana P, Geiger A. Midgut expression of immune-related genes in Glossina palpalis gambiensis challenged with Trypanosoma brucei gambiense. Front Microbiol. 2014;5:609.
130. Horáková E, Changmai $P$, Vancová M, Sobotka R, Van Den Abbeele J, Vanhollebeke $\mathrm{B}$, et al. The Trypanosoma brucei TbHrg protein is a heme transporter involved in the regulation of stage-specific morphological transitions. J Biol Chem. 2017;292:6998-7010.

131. Hyseni C, Kato AB, Okedi LM, Masembe C, Ouma JO, Aksoy S, et al. The population structure of Glossina fuscipes fuscipes in the Lake Victoria basin in Uganda: implications for vector control. Parasit Vectors. 2012;5:222.

132. Kamidi CM, Saarman NP, Dion K, Mireji PO, Ouma C, Murilla G, et al. Multiple evolutionary origins of Trypanosoma evansi in Kenya. PLoS Negl Trop Dis. 2017; 11:e0005895

133. Manangwa O, Nkwengulila G, Ouma JO, Mramba F, Malele I, Dion K, et al. Genetic diversity of Glossina fuscipes fuscipes along the shores of Lake Victoria in Tanzania and Kenya: implications for management. Parasit Vectors. 2017;10:268

134. Manangwa O, Ouma J, Malele I, Msangi A, Mramba F, Nkwengulila G. Distribution and population size of Glossina fuscipes fuscipes (tsetse flies) along the Lake Victoria, for trypanosomiasis management in Tanzania. Livest Res Rural Dev. 2015;27:31.

135. Matetovici I, Caljon G, Van Den Abbeele J. Tsetse fly tolerance to T brucei infection: transcriptome analysis of trypanosome-associated changes in the tsetse fly salivary gland. BMC Genomics. 2016;17:971.

136. Mwangi S, Attardo G, Suzuki Y, Aksoy S, Christoffels A. TSS seq based core promoter architecture in blood feeding tsetse fly (Glossina morsitans morsitans) vector of trypanosomiasis. BMC Genomics. 2015;16:722.

137. Okeyo WA, Saarman NP, Mengual M, Dion K, Bateta R, Mireji PO, et al. Temporal genetic differentiation in Glossina pallidipes tsetse fly populations in Kenya. Parasit Vectors. 2017;10:471.

138. Opiro R, Saarman NP, Echodu R, Opiyo EA, Dion K, Halyard A, et al. Evidence of temporal stability in allelic and mitochondrial haplotype diversity in populations of Glossina fuscipes fuscipes (Diptera: Glossinidae) in northern Uganda. Parasit Vectors. 2016;9:258.

139. Opiro R, Saarman NP, Echodu R, Opiyo EA, Dion K, Halyard A, et al. Genetic diversity and population structure of the tsetse fly Glossina fuscipes fuscipes (Diptera: Glossinidae) in northern Uganda: implications for vector control. PLoS Negl Trop Dis. 2017;11:e0005485.

140. Savage AF, Kolev NG, Franklin JB, Vigneron A, Aksoy S, Tschudi C. Transcriptome profiling of Trypanosoma brucei development in the tsetse fly vector Glossina morsitans. PLoS One. 2016;11:e0168877.

141. Scolari F, Benoit JB, Michalkova V, Aksoy E, Takac P, Abd-Alla AMM, et al. The spermatophore in Glossina morsitans morsitans: insights into male contributions to reproduction. Sci Rep. 2016;6:20334 Article number.

142. Telleria EL, Benoit JB, Zhao X, Savage AF, Regmi S, Alves-e-Silva TL, et al. Insights into the trypanosome-host interactions revealed through transcriptomic analysis of parasitized tsetse fly salivary glands. PLoS Negl Trop Dis. 2014:8:e2649.

143. Tihon E, Imamura H, Dujardin J-C, Van Den Abbeele J. Evidence for viable and stable triploid Trypanosoma congolense parasites. Parasit Vectors. 2017;10:468.

144. Tsagmo Ngoune JM, Njiokou F, Loriod B, Kame-Ngasse G, Fernandez-Nunez $\mathrm{N}$, Rioualen $\mathrm{C}$, et al. Transcriptional profiling of midguts prepared from Trypanosoma/T congolense-positive Glossina palpalis palpalis collected from two distinct Cameroonian foci: coordinated signatures of the midguts' remodeling as T congolense-supportive niches. Front Immunol. 2017:8:876.

145. Waespy M, Gbem TT, Elenschneider L, Jeck A-P, Day CJ, Hartley-Tassell L, et al. Carbohydrate recognition specificity of trans-sialidase lectin domain from Trypanosoma congolense. PLoS Negl Trop Dis. 2015;9:e0004120.

146. Zhao X, Silva TLA E, Cronin L, Savage AF, O'Neill M, Nerima B, et al. Immunogenicity and serological cross-reactivity of saliva proteins among different tsetse species. PLoS Negl Trop Dis. 2015;9:e0004038.

147. Geiger A, Malele II, Abd-Alla AMM, Njiokou F. Blood feeding tsetse flies as hosts and vectors of mammals-pre-adapted African Trypanosoma: current and expected research directions 2018; https://doi.org/10.1186/s12866-018-1281-x.

148. Brelsfoard C, Tsiamis G, Falchetto M, Gomulski LM, Telleria E, Alam U, et al. Presence of extensive Wolbachia symbiont insertions discovered in the genome of its host Glossina morsitans morsitans. PLoS Negl Trop Dis. $2014 ; 8: \mathrm{e} 2728$

149. Doudoumis V, Alam U, Aksoy E, Abd-Alla AMM, Tsiamis G, Brelsfoard C, et al. Tsetse-Wolbachia symbiosis: comes of age and has great potential for pest and disease control. J Invertebr Pathol. 2013;112:S94-103.

150. Schneider DI, Riegler M, Arthofer W, Merçot H, Stauffer C, Miller WJ. Uncovering Wolbachia diversity upon artificial host transfer. PLoS One. 2013; 8:e82402. 
151. Miller WJ. Bugs in transition: the dynamic world of Wolbachia in insects. PLoS Genet. 2013;9:e1004069.

152. Schneider DI, Klasson L, Lind AE, Miller WJ. More than fishing in the dark: PCR of a dispersed sequence produces simple but ultrasensitive Wolbachia detection. BMC Microbiol. 2014;14:121.

153. Wamwiri FN, Alam U, Thande PC, Aksoy E, Ngure RM, Aksoy S, et al. Wolbachia, Sodalis and trypanosome co-infections in natural populations of Glossina austeni and Glossina pallidipes. Parasit Vectors. 2013;6:232.

154. Wamwiri FN, Ndungu K, Thande PC, Thungu DK, Auma JE, Ngure RM. Infection with the secondary tsetse-endosymbiont Sodalis glossinidius (Enterobacteriales: Enterobacteriaceae) influences parasitism in Glossina pallidipes (Diptera: Glossinidae). J Insect Sci. 2014;14:272.

155. Wamwiri FN, Changasi RE. Tsetse flies (Glossina) as vectors of human African trypanosomiasis: a review. BioMed Res Int. 2016;2016:8 pages.

156. Mbewe NJ, Mweempwa C, Guya S, Wamwiri FN. Microbiome frequency and their association with trypanosome infection in male Glossina morsitans centralis of Western Zambia. Vet Parasitol. 2015;211:93-8.

157. Bossard G, Bartoli M, Fardeau M-L, Holzmuller P, Ollivier B, Geiger A. Characterization of recombinant Trypanosoma brucei gambiense translationally controlled tumor protein (rTbgTCTP) and its interaction with Glossina midgut bacteria. Gut Microbes. 2017;8:413-27.

158. Caers J, Boonen K, Van Den Abbeele J, Van Rompay L, Schoofs L, Van Hiel MB. Peptidomics of neuropeptidergic tissues of the tsetse fly Glossina morsitans morsitans. J Am Soc Mass Spectrom. 2015;26:2024-38.

159. Caers J, Janssen T, Van Rompay L, Broeckx V, Van Den Abbeele J, Gäde G, et al. Characterization and pharmacological analysis of two adipokinetic hormone receptor variants of the tsetse fly, Glossina morsitans morsitans. Insect Biochem Mol Biol. 2016;70:73-84.

160. Caers J, Peymen K, Van Hiel MB, Van Rompay L, Van Den Abbeele J, Schoofs $L$, et al. Molecular characterization of a short neuropeptide F signaling system in the tsetse fly, Glossina morsitans morsitans. Gen Comp Endocrinol. 2016;235:142-9.

161. Caers J, Van Hiel MB, Peymen K, Zels S, Van Rompay L, Van Den Abbeele J, et al. Characterization of a neuropeptide F receptor in the tsetse fly, Glossina morsitans morsitans. J Insect Physiol. 2016;93-94:105-11.

162. Farikou O, Njiokou F, Cuny G, Geiger A. Microsatellite genotyping reveals diversity within populations of Sodalis glossinidius, the secondary symbiont of tsetse flies. Vet Microbiol. 2011;150:207-10.

163. Geiger A, Ponton F, Simo G. Adult blood-feeding tsetse flies, trypanosomes, microbiota and the fluctuating environment in sub-Saharan Africa. ISME J. 2015;9:1496-507.

164. Geiger A, Tchicaya B, Rihet P. Technical data of the transcriptomic analysis performed on tsetse fly symbionts, Sodalis glossinidius and Wigglesworthia glossinidia, harbored, respectively by non-infected, Trypanosoma brucei gambiense infected and self-cured Glossina palpalis gambiensis tsetse flies. Genomics Data. 2015;4:133-6.

165. Hamidou SI, Tchicaya B, Loriod B, Rihet P, Geiger A. Identification of overexpressed genes in Sodalis glossinidius inhabiting trypanosome-infected self-cured tsetse flies. Front Microbiol. 2014;5:255

166. Hamidou Soumana I, Tchicaya B, Simo G, Geiger A. Comparative gene expression of Wigglesworthia inhabiting non-infected and Trypanosoma brucei gambiense-infected Glossina palpalis gambiensis flies. Front Microbiol. 2014:5:620.

167. Hrusa G, Farmer W, Weiss BL, Applebaum T, Roma JS, Szeto L, et al. TonBdependent heme iron acquisition in the tsetse fly symbiont Sodalis glossinidius. Appl Environ Microbiol. 2015;81:2900-9.

168. Maltz MA, Weiss BL, O'Neill M, Wu Y, Aksoy S. OmpA-mediated biofilm formation is essential for the commensal bacterium Sodalis glossinidius to colonize the tsetse fly gut. Appl Environ Microbiol. 2012;78:7760-8.

169. Michalkova V, Benoit JB, Attardo GM, Medlock J, Aksoy S. Amelioration of reproduction-associated oxidative stress in a viviparous insect is critical to prevent reproductive senescence. PLoS One. 2014;9:e87554.

170. Michalkova V, Benoit JB, Weiss BL, Attardo GM, Aksoy S. Vitamin B6 generated by obligate symbionts is critical for maintaining proline homeostasis and fecundity in tsetse flies. Appl Environ Microbiol. 2014;80: 5844-53.

171. Vigneron A, Masson F, Vallier A, Balmand S, Rey M, Vincent-Monégat C, et al. Insects recycle endosymbionts when the benefit is over. Curr Biol. 2014;24: 2267-73.

172. Weiss BL, Savage AF, Griffith BC, Wu Y, Aksoy S. The peritrophic matrix mediates differential infection outcomes in the tsetse fly gut following challenge with commensal, pathogenic, and parasitic microbes. J Immunol. 2014;193:773-82.

173. Scolari F, Attardo GM, Aksoy E, Weiss BL, Savini G, Takac P, Abd-Alla AMM, Parker AG, Aksoy S, Malacrida AR. Symbiotic microbes affect the expression of male reproductive genes in Glossina m. morsitans. BMC Microbiol. 2018; https://doi.org/10.1186/s12866-018-1289-2.

174. Doudoumis V, Augustinos AA, Saridaki A, Parker AG, Abd-Alla AMM, Bourtzis $\mathrm{K}$, et al. Different laboratory populations similar bacterial profile? The case of Glossina palpalis gambiensis. BMC Microbiol. 2018; https://doi.org/10.1186/ s12866-018-1290-9.

175. Seck MT, Pagabeleguem S, Bassene MD, Fall AG, Diouf TAR, Sall B, et al. Quality of sterile male tsetse after long distance transport as chilled irradiated pupae. PLoS Negl Trop Dis. 2015;9:e0004229.

176. Kariithi HM, Yao X, Yu F, Teal PE, Verhoeven CP, Boucias DG. Responses of the housefly, Musca domestica, to the hytrosavirus replication: impacts on host's vitellogenesis and immunity. Front Microbiol. 2017;8:583.

177. Boucias D, Baniszewski J, Prompiboon P, Lietze V, Geden C. Enhancement of the Musca domestica hytrosavirus infection with orally delivered reducing agents. J Invertebr Pathol. 2015;124:35-43.

178. Gilbert JA, Medlock J, Townsend JP, Aksoy S, Ndeffo Mbah M, Galvani AP. Determinants of human African trypanosomiasis elimination via paratransgenesis. PLoS Negl Trop Dis. 2016;10:e0004465.

179. Aksoy S, Caccone A, Galvani AP, Okedi LM. Glossina fuscipes populations provide insights for human African trypanosomiasis transmission in Uganda. Trends Parasitol [Internet]. 2013;29:394-406 Available from: http://www. sciencedirect.com/science/article/pii/S1471492213001050; https://doi.org/10. 1016/j.pt.2013.06.005.
Ready to submit your research? Choose BMC and benefit from:

- fast, convenient online submission

- thorough peer review by experienced researchers in your field

- rapid publication on acceptance

- support for research data, including large and complex data types

- gold Open Access which fosters wider collaboration and increased citations

- maximum visibility for your research: over $100 \mathrm{M}$ website views per year

At BMC, research is always in progress.

Learn more biomedcentral.com/submissions 